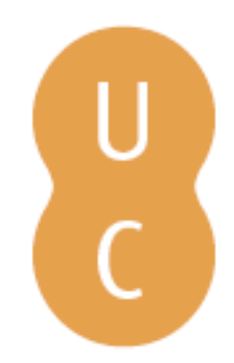

\title{
nommalina
}

\section{Formação continuada de professores no Programa Agrinho: uma experiência formativa em rede}

\author{
Autor(es): $\quad$ Torres, Patricia Lupion \\ Publicado por: Imprensa da Universidade de Coimbra \\ URL \\ persistente: URI:http://hdl.handle.net/10316.2/47386 \\ DOI: $\quad$ DOI:https://doi.org/10.14195/978-989-26-1716-9_10 \\ Accessed : $\quad$ 26-Apr-2023 11:04:36
}

A navegação consulta e descarregamento dos títulos inseridos nas Bibliotecas Digitais UC Digitalis, UC Pombalina e UC Impactum, pressupõem a aceitação plena e sem reservas dos Termos e Condições de Uso destas Bibliotecas Digitais, disponíveis em https://digitalis.uc.pt/pt-pt/termos.

Conforme exposto nos referidos Termos e Condições de Uso, o descarregamento de títulos de acesso restrito requer uma licença válida de autorização devendo o utilizador aceder ao(s) documento(s) a partir de um endereço de IP da instituição detentora da supramencionada licença.

Ao utilizador é apenas permitido o descarregamento para uso pessoal, pelo que o emprego do(s) título(s) descarregado(s) para outro fim, designadamente comercial, carece de autorização do respetivo autor ou editor da obra.

Na medida em que todas as obras da UC Digitalis se encontram protegidas pelo Código do Direito de Autor e Direitos Conexos e demais legislação aplicável, toda a cópia, parcial ou total, deste documento, nos casos em que é legalmente admitida, deverá conter ou fazer-se acompanhar por este aviso.

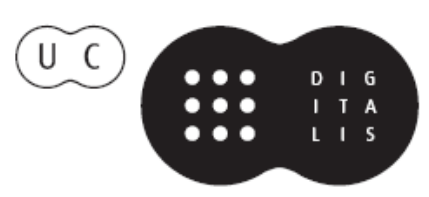



PATRICIA LUPION TORRES

Pontifícia Universidade Católica do Paraná - PUCPR

patorres@terra.com.br

\section{FORMAÇÃO CONTINUADA DE PROFESSORES NOPROGRAMA AGRINHO: UMA EXPERI ÊNCIA FORMATIVA EM REDE}

\section{Fundamentos Teóricos do Programa Agrinho}

Voltado para as crianças e jovens paranaenses o Programa Agrinho foi criado no marco do compromisso institucional do Serviço Nacional de Aprendizagem Rural - Administração Regional do Estado do Paraná. Entre suas atribuições o SENARPR tem a responsabilidade basilar da promoção social da família do trabalhador rural. Assim trabalhar com crianças e jovens, constitui uma prioridade institucional. A implementação do Programa nas escolas repete desde sua concepção os seguintes passos como estratégia operacional: Seleção de conteúdos, contratação de autores e formadores especialistas, elaboração de materiais no formato de recursos educacionais abertos para alunos e professores, mobilização escolar, capacitação docente, desenvolvimento de projetos e atividades por docentes e discentes, acompanhamento do programa e culminância das ações no concurso e festa de encerramento.

Desde seu nascimento em 1995 o Programa Agrinho tem como fundamentos o debate complexo, desvelando a interdependência entre relações frequentemente exibidas como antagônicas, fato que garante uma proposta crítica, orientada para a tão necessária formação de alunos e professores pesquisadores. Assim a concepção do programa repousa nos seguintes pressupostos: na transdisciplinaridade, na pesquisa como prática educacional alvitrada por Bochniak (1998) e Torres (2002), e na colaboração na perspectiva proposta por Torres (2002) em sua tese de doutorado. 
Pretende-se com essa proposta romper com modelos pedagógicos que se fundamentam no paradigma do ensino, centrado na figura do professor. Pretende-se ainda, a superação da fragmentação do processo educacional que estrutura os conteúdos em disciplinas compartimentando os saberes, de modo a alcançar uma prática pedagógica que contemple uma abordagem transdisciplinar.

Vale esclarecer que nessa proposta o significado da transdisciplinaridade para Torres e Behrens (2014, p 19) consiste em uma visão que apresenta o "grau máximo de relações na integração de disciplinas que permitem a interconexão dos conteúdos, no sentido de auxiliar na unificação dos conhecimentos e na compreensão da realidade".

As autoras ainda destacam que "trata-se de uma interação de disciplinas que vai além da justaposição de várias disciplinas, como nos processos da interdisciplinaridade e da multidisciplinaridade" (Torres e Behrens, 2014, p. 19).

Para que essa real integração de disciplinas ocorra a escola necessita ser preparada para implantar a transversalidade, proposta basilar das temáticas de relevância sócio ambiental selecionadas para o desenvolvimento dos trabalhos do Agrinho. Reconhece-se que embora existam tentativas implementadas de práticas transversais em escolas ainda não foi possível a transposição real na maioria das instituições de ensino. Assim para a concretização desse eixo epistemológico, faz-se necessário uma proposta metodológica coerente com tais princípios teóricos, "pois, percebe-se, de fato, que especialmente em relação às questões da "interdisciplinaridade" e da "transversalidade" a escola ainda se encontra diante de um enorme descompasso entre teoria e prática" (Torres e Bochniak 2003, p. 3). Para buscar a transposição acima mencionada, foi que se optou por trabalhar com os fundamentos metodológicos da pesquisa, da transdisciplinaridade e da colaboração que, sem se constituir em uma receita, apresenta procedimentos práticos a serem desenvolvidos em espaços educacionais a fim de alcançar os objetivos teóricos e práticos de uma educação crítica, criativa e reflexiva que transforme estudantes e professores em pesquisadores capazes de produzir novos conhecimentos.

Vale destacar que para alcançar a concretização da proposta acima apresentada optou-se por desde o início do programa investir em um programa de formação continuada para professores do ensino público e privado. No 
início do programa, após esse processo formativo, os docentes que aderiam ao programa desenvolviam com seus alunos diversas atividades no formato de projetos. Com o passar dos anos as ações desenvolvidas pelos discentes se ampliaram e passaram a envolver a comunidade extrapolando os muros escolares.

Assim, desde 1995, a estratégia do Programa Agrinho centra-se no desenvolvimento de projetos por docentes e discentes, que visem uma educação para a sustentabilidade. Para tal, todos os alunos envolvidos com o programa recebem materiais paradidáticos visando enriquecer os conteúdos trabalhados de forma transversal ao currículo e auxiliar nos debates desenvolvidos nas fases iniciais dos projetos.

Os projetos desenvolvidos nas escolas são enviados para a sede do SENARPR de forma voluntária pelos professores e são avaliados por uma banca examinadora composta por representantes dos parceiros e por professores universitários. Os melhores trabalhos recebem um reconhecimento de seu mérito na forma de diplomação e premiação. Desta forma temos uma constante avaliação da aceitação e da compreensão dos materiais, das palestras, bem como um acompanhamento dos trabalhos desenvolvidos a campo.

Cabe aqui registrar o número de turmas e de alunos atendidos desde o lançamento do Programa:

TABELA 1: Número de discentes por ano e número de turmas envolvidos no Programa Agrinho

\begin{tabular}{|l|r|r|}
\hline ANO & TURMAS & \multicolumn{1}{|c|}{ ALUNOS } \\
\hline 1.996 & 351 & 7.443 \\
\hline 1.997 & 13.983 & 364.880 \\
\hline 1.998 & 26.692 & 696.597 \\
\hline $1.999\left(^{*}\right)$ & 47.275 & 1.233 .463 \\
\hline 2.000 & 42.926 & 1.227 .135 \\
\hline 2.001 & 45.791 & 1.244 .021 \\
\hline 2.002 & 55.147 & 1.625 .660 \\
\hline 2.003 & 58.695 & 1.730 .900 \\
\hline 2.004 & 54.762 & 1.588 .118 \\
\hline 2.005 & 54.730 & 1.587 .171 \\
\hline
\end{tabular}




\begin{tabular}{|c|c|r|}
\hline ANO & TURMAS & ALUNOS \\
\hline 2.006 & 56.644 & 1.642 .676 \\
\hline 2.007 & 51.800 & 1.553 .997 \\
\hline 2.008 & 53.708 & 1.526 .935 \\
\hline 2.009 & 46.122 & 1.361 .474 \\
\hline 2.010 & 37.391 & 1.014 .640 \\
\hline 2.011 & 41.016 & 1.107 .433 \\
\hline 2.012 & 41.343 & 1.044 .586 \\
\hline 2.013 & 23.746 & 831.131 \\
\hline 2.014 & 41.296 & 1.114 .992 \\
\hline 2.015 & 26.617 & 718.653 \\
\hline 2.016 & 26.617 & 718.659 \\
\hline Total & 846.652 & 23.940 .564 \\
\hline
\end{tabular}

Fonte: SENARPR

Em 22 anos de atividades, o Agrinho incentivou a comunidade escolar a debater questões - as vezes ausentes das salas de aula - referentes a sustentabilidade nas dimensões propostas por Sacks (2000): social, econômica, ecológica, cultural, espacial, política e ambiental . Toda uma geração participou da construção de uma nova consciência social. Milhares de palestras de formação continuada de professores foram realizadas nos 22 de atividades do programa, objetivando uma reflexão dos docentes sobre a sua prática pedagógica.

\section{A Formação de Professores do Programa Agrinho}

Nos primeiros anos de sua implantação todo o trabalho formativo de professores se desenvolvia em formações presenciais no formato de palestras ou oficinas presenciais ao mesmo tempo em que eram desenvolvidas diversas atividades com os estudantes nas escolas. São ainda distribuídos livros para os docentes, cuja autoria é coletiva, de diversos professores pesquisadores de instituições de ensino superior brasileiras e estrangeiras. A congregação de tantos especialistas para a produção de materiais paradidáticos e para a formação dos professores atende a deliberação n. ${ }^{\circ} 04 / 13$ do 
Conselho Estadual de Educação que estabelece as normas estaduais para a Educação Ambiental no Sistema Estadual de Ensino do Paraná e em seu capítulo I, artigo $3 .^{\circ}$ dispõe:

IV - o fortalecimento da parceria entre Ensino Superior e Educação Básica, como fator de incentivo à utilização de inovações tecnológicas e metodológicas, por intermédio da formação continuada dos profissionais da educação e comunidade, que contribuam para a sustentabilidade (CEE, 2013, p.4).

A Diretora da Divisão de Ciência da Água e Secretária do Programa Hidrológico Internacional da Unesco - Blanca Jiménez-Cisneros - ao comentar sobre os livros distribuídos no formativo do programa destaca que "graças a esses materiais e o Programa Agrinho, o Estado de Paraná, por certo, terá uma nova geração de cidadãos que podem cuidar melhor de sua saúde física e mental, preservar e gerenciar a natureza, mas acima tudo contribuir para um mundo melhor." (2014, p.13). Jiménez-Cisneros (2014, p13), ainda destaca que para ela "Esse processo se destina a promover uma educação crítica, criativa e reflexiva, que são os elementos indispensáveis para a construção de uma nova sociedade".

A formação on line, teve seu início em 2011 com uma proposta piloto que investiu na preparação dos professores para trabalhar com a pesquisa como prática pedagógica, a colaboração e a transversalidade, propostas fundantes do Programa Agrinho. Desta forma, para a implementação da modalidade on line na formação de professores no programa desenvolveu-se a estruturação da proposta em três etapas:

1. Produção de um objeto de aprendizagem composto por 4 módulos

2. Preparação do plano de trabalho composto por 6 unidades.

3. Realização de cursos de formação de professores, completamente à distância, com uma carga de trabalho de 40 horas.

Os cursos foram desenvolvidos no ambiente virtual de aprendizagem Eureka com o uso de mídias integradas. Esse ambiente possui uma função central para a organização do curso: o "plano de trabalho". Essa função esta- 
belece um roteiro que guia o aprendiz em seu processo de aprendizagem. No "plano de trabalho" foram organizados todos os módulos funcionais e atividades do curso dos cursos do Programa Agrinho, como se vê no exemplo a seguir.

FIGURA 1: Plano de Trabalho do Eureka

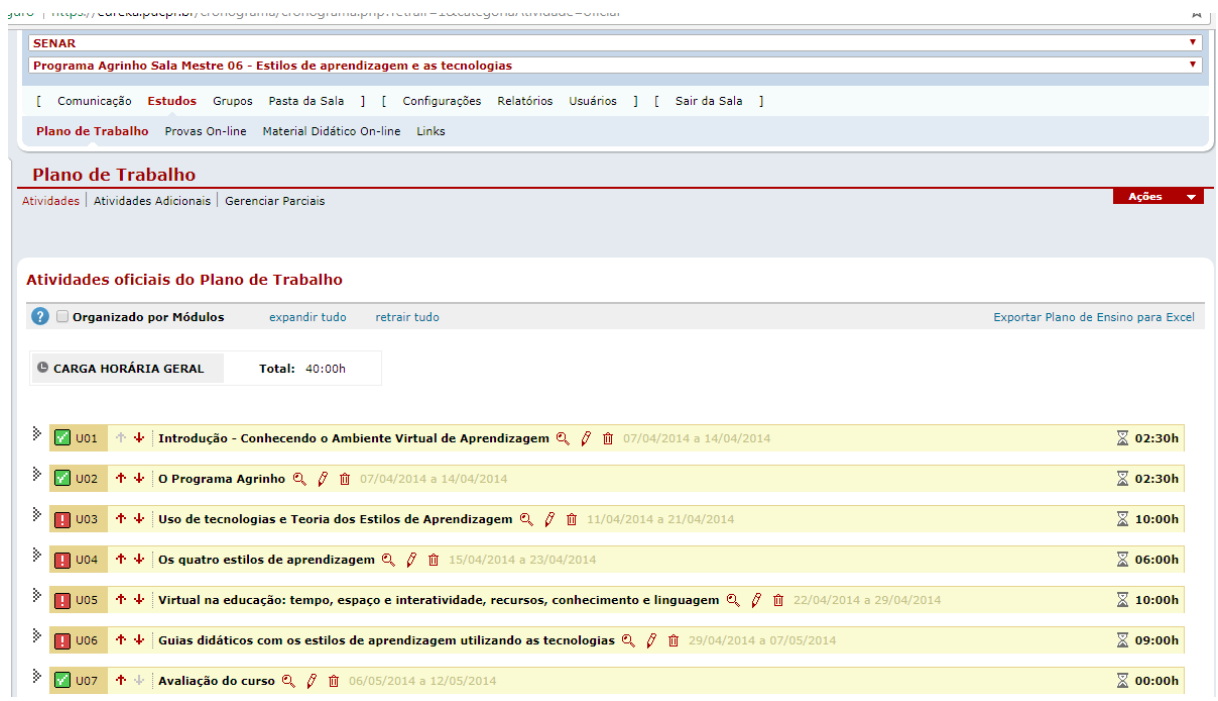

Fonte: EUREKA

A metodologia definida focava numa formação flexível e colaborativa, apoiada em tutoria. Assim foi que se definiu pelo uso de Objetos de Aprendizagem já que esse recurso apresenta benefícios para esse tipo de situação de aprendizagem (Torres et al., 2010). O AVA Eureka possui uma ferramenta denominada SAAW para o armazenamento dos objetos de aprendizagem que foi utilizada para apresentar o conteúdo do curso. As telas a seguir mostram exemplos de páginas dos objetos de aprendizagem usados nos cursos. 


\section{FIGURA 2: Objeto de Aprendizagem - Curso Escola e Tecnologias Digitais na Infância}

\section{ESCOLA E TECNOLOGIAS DIGITAIS NA INFÂNCIA}

Escola e tecnologias digitais na infância (Módulo 01)

05. Integrando a tecnologia com a prática pedagógica

Nesse sentido, procuraremos num primeiro momento, dar conta de um conjunto de fatores que consideramos importante reunir para que 0 professor/educador integre com sucesso a tecnologia na sua prática pedagógica renovando-a. Num segundo momento, apresentamos algumas situações concretas de uso das tecnologias na sala de aula, ligadas à exploração de conteúdos curriculares específicos,

designadamente ao nível do desenvolvimento da linguagem oral, da escrita e da matemática

\section{క̧ OBSERVAÇÃO}

Escolhemos estas áreas por serem cruciais, mas lembrando que as atividades aqui desenvolvidas se interligam desejavelmente com todas as outras que importam explorar nos contextos quer de educação infantil, quer do ensino fundamental, tendo em vista o desenvolvimento integral da criança. Ou seja, a comunicação oral, a escrita e a matemática devem desejavelmente ligar-se quer ao conhecimento da comunidade, do meio e do mundo que importa promover, quer ao desenvolvimento psicomotor, também muito relevante nesta faixa etária, quer, ainda, ao desenvolvimento pessoal e social da criança.

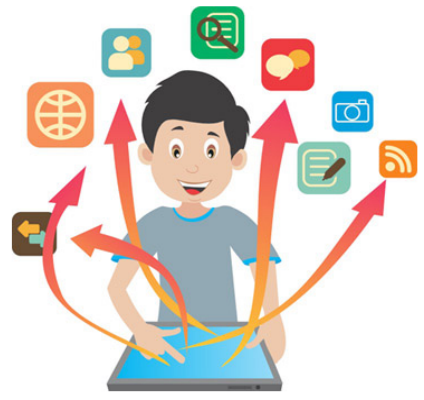

Fonte: SAAW_EUREKA

FIGURA 3: Objeto de Aprendizagem - Curso Estilos de Aprendizagem e as Tecnologias

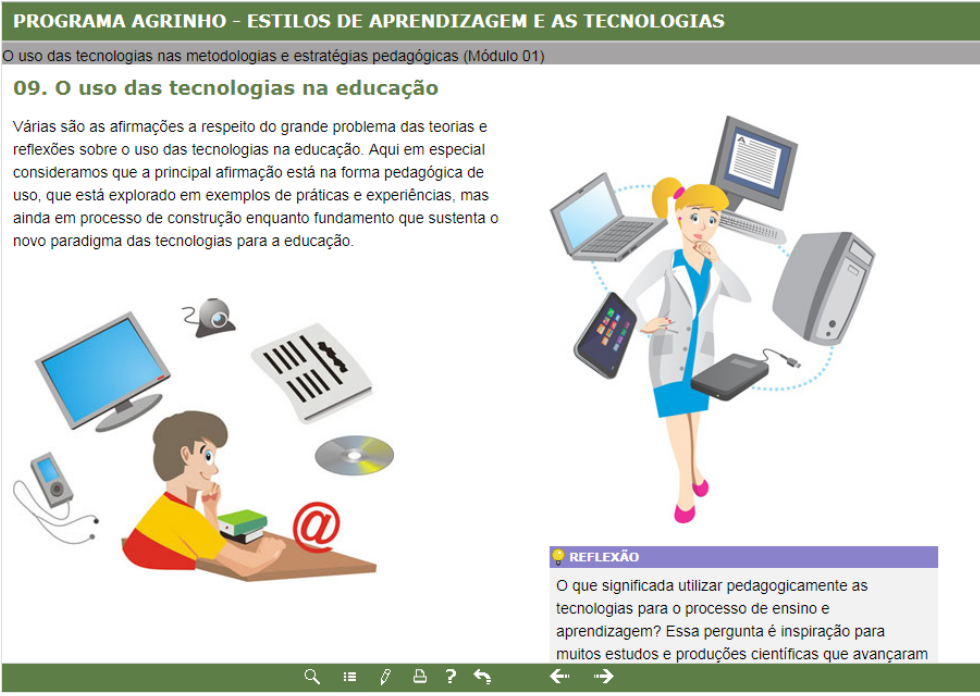

Fonte: SAAW_EUREKA 
FIGURA 4: Objeto de Aprendizagem - Programa Agrinho: Bases Teóricas

\section{PROGRAMA AGRINHO - BASES TEÓRICAS}

ATIVIDADES DA PEDAGOGIA DA PESQUISA (Módulo 03)

02. Pedagogia da Pesquisa

Na Pedagogia da Pesquisa, os alunos podem e devem exprimir suas idéias, questionar o saber estabelecido, construir

significações e ressignificações e, principalmente, resgatar o prazer do saber.

Busca-se superar o paradigma da escola tradicional, de ensino memorístico, que coloca sobre o professor a responsabilidade de selecionar a "verdade" científica a ser apresentada aos alunos, a quem resta simplesmente memorizar o que the é apresentado.

A atitude interdisciplinar de pesquisa tem como base a concepção de interdisciplinaridade de Bochniak (1993) adotada nesta proposta, em que alunos e professores vivenciam a superação de inúmeras visões fragmentadas e (ou) dicotômicas existentes no cotidiano de nossas escolas, principalmente a superação da visão dicotômica entre teoria e prática

Ao propor aos alunos uma atitude mais reflexiva o professor conduz os discentes a assumirem uma posição de sujeitos pesquisadores.

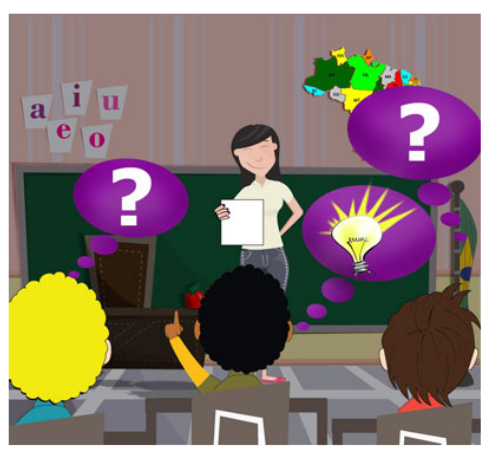

Fonte: SAAW_EUREKA

Após a experiência piloto de implantação e desenvolvimento de 97 turmas definiu-se por ampliar o número de cursos de formação on line do Programa Agrinho. A partir de 2012 encontra-se definitivamente consolidada a proposta de formação continuada on line de professores da rede municipal e estadual do Estado do Paraná. Na tabela 2 são apresentados os dados quantitativos desta experiência.

TABEla 2: Número de participantes do curso a distância para a formações de professores por ano e número de turmas - 2011-2017.

\begin{tabular}{|c|c|c|}
\hline ANO & TURMAS & PARTICIPANTES \\
\hline 2011 & 97 & 2.161 \\
\hline 2012 & 196 & 4.556 \\
\hline 2013 & 191 & 5.928 \\
\hline 2014 & 173 & 6.143 \\
\hline 2015 & 171 & 5.573 \\
\hline 2016 & 180 & 5.848 \\
\hline $2017^{*}$ & 147 & 3967 \\
\hline
\end{tabular}

* Dados de janeiro a setembro de 2017

Fonte: Banco de dados do SENARPR 
Com uma carga horária de $\mathbf{4 0}$ horas todos cursos on line são gratuitos e tem em seu cerne a mesma perspectiva do Programa, ou seja, são fundados na colaboração, na transdisciplinaridade e na pesquisa. Pretende-se com essa proposta formativa a superação do paradigma do ensino e a implementação do paradigma da comunicação (Trindade \& Cosme, 2010) com uma visão complexa, sistêmica, integradora e participativa preocupada não somente com a interconexão entre temas, mas também com a promoção de uma postura ética, reflexiva, fraterna e transformadora (Torres e Saheb, 2015) .

$\mathrm{Na}$ atualidade a formação continuada de professores permanece sendo realizada por meio de palestras presenciais e dos seguintes cursos on line disponibilizados pelo SENARPR (http://senardigital.com/cursos.php) para professores da Educação Infantil e do Ensino Fundamental de escolas públicas e privadas de todo o estado do Paraná - Brasil:

- Aprendizagem colaborativa e mapas conceituais

- Interatividade e metodologia de projetos

- Atuação dos educadores facilitando a autoria colaborativa de jogos pelos alunos

- Escola digital e o educador 3.0

- Estilos de aprendizagem e as tecnologias

- Inovação na educação básica e tecnologias educacionais: aplicando os quatro Rs do REA

- Portfólio como ferramenta metodológica e avaliativa

- Novas linguagens, novos desafios: a internet no contexto escolar.

- Escola e tecnologias digitais na infância

- Mapas do conhecimento com recursos educacionais abertos aplicados a coaprendizagem baseada na coinvestigação

- Tecnologias digitais, linguagem e currículo: investigação, construção do conhecimento e produção de narrativas

Esses cursos têm suas atividades pensadas de modo a levar os docentes participantes a repensarem suas práticas cotidianas após refletirem sobre elas. A auto avaliação de seu processo formativo tanto em relação a sua fundamentação teórica quanto em relação à incorporação do aprendido 
em sua prática diária auxiliam nesse processo de reflexão e revisão de sua prática pedagógica.

\section{Algumas considerações}

As atividades docentes muitas vezes estão centradas no paradigma do ensino (Trindade \& Cosme, 2010) ou seja na prática de ensinar, de reproduzir conhecimentos ou ainda de aplicar técnicas. Pretendendo uma mudança foi que se pensou no Programa Agrinho processos de formação continuada que articulem teoria e prática com espaços de produção de conhecimento de forma colaborativa. Foi assim que na formação continuada desse programa, "as atitudes e a qualificação dos professores [ foi ] centrada no eixo da reflexão individual e coletiva sobre a prática pedagógica proposta na ação docente em sala de aula" (Behrens, 2005, p. 140).

Pretende-se nesse processo de educação continuada de professores do Programa Agrinho formar um docente reflexivo, pesquisador atento a questão da sustentabilidade em todas as suas dimensões, ou seja pretende-se desenvolver uma formação continuada em uma perspectiva complexa, que considere o sujeito como fazedor da historia atual e futura. Como resultado desse processo formativo tem-se todos os anos, milhares de projetos desenvolvidos por alunos e professores envolvendo toda a comunidade escolar.

\section{Referências bibliográficas}

BEHRENS, M A. (2005). O paradigma emergente e a prática pedagógica. Petrópolis, RJ: Vozes.

BOCHNIAK, R. (2 Ed.) (1998) Questionar o conbecimento: a interdisciplinaridade na escola... e fora dela. São Paulo: Loyola.

CCE - Conselho Estadual de Educação. Educação Ambiental no Sistema Estadual de ensino do Paraná - capítulo I, artigo 3. ․ Disponível em: http://www.cee.pr.gov.br/ arquivos/File/pdf/Deliberacoes/2013/deliberacao_04_13.pdf.

SACHS, I. (2000). Caminhos para o desenvolvimento sustentável. Rio de Janeiro: Garamond. 
TRINDADE, R; COSME, A. (2010). Educar e aprender na escola: questões, desafios e respostas pedagógicas. Porto: Fundação Manuel Leão.

TORRES, P. L. (2002) Laboratório on line de aprendizagem: uma proposta crítica de aprendizagem colaborativa para a educação. Tese (Doutorado em Engenharia da Produção). Universidade Federal de Santa Catarina, Florianópolis.

TORRES, P. L.; BOCHNIAK, R. (2003). Uma leitura para os temas transversais: ensino fundamental. Curitiba: Serviço Nacional de Aprendizagem Rural - SENAR.

TORReS, L. P.; HILÚ, L.; TARRIT, C. R.; KOWALSKI P. G. R. (2010). "SAAW: um relato de experiência de desenvolvimento de objetos de aprendizagem." AFIRSE 2010. Lisboa

TORRES, L. P.; BEHRENS, M. A. (2014). Complexidade, transdisciplinaridade e produção do conhecimento. In: P. L. Torres (Org.). Redes e conexões na produção do conhecimento. Curitiba: Serviço Nacional de Aprendizagem Rural - SENAR.

TORRES, P. L.; SAHEB, D. (2015). Educação continuada de professores: uma experiência de interdisciplinaridade na busca da transdisciplinaridade. In M. A. Behrens, R. T. Ens. (Org.). Complexidade e transdisciplinaridade - Novas perspectivas teóricas e práticas para a formação de professores v. 1 (175-198). Curitiba: Appris. 